\title{
Correction to: Outcomes of parathyroidectomy versus calcimimetics for secondary hyperparathyroidism and kidney transplantation: a propensity-matched analysis
}

\author{
Ezra Y. Koh ${ }^{1}$ • Willemijn Y. van der Plas ${ }^{2} \cdot$ Roderick R. Dulfer ${ }^{3} \cdot$ Robert A. Pol $^{2} \cdot$ Schelto Kruijff $^{2}$ - Joris I. Rotmans ${ }^{4}$. \\ Natasha Appelman-Dijkstra ${ }^{4}$. Abbey Schepers ${ }^{5}$. Martin H. de Borst ${ }^{6}$ - Ewout J. Hoorn ${ }^{7}$. Tessa M. van Ginhoven ${ }^{3}$.

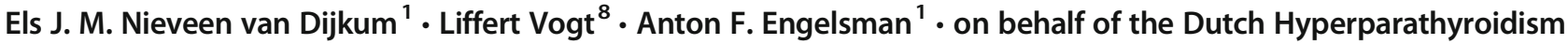 \\ Study Group
}

Published online: 7 January 2021

(C) Springer-Verlag GmbH Germany, part of Springer Nature 2021

Correction to: Langenbeck's Archives of Surgery (2020) 405:851-859.

https://doi.org/10.1007/s00423-020-01953-5

The original version of this article unfortunately contained a mistake on the fifth and eleventh author names, from Schelto Kruijf to Schelto Kruijff and from Tessa van Ginhoven to Tessa M. van Ginhoven.

The corrected author names are shown below.

Schelto Kruijff and Tessa M. van Ginhoven

Publisher's note Springer Nature remains neutral with regard to jurisdictional claims in published maps and institutional affiliations.

The online version of the original article can be found at https://doi.org/ 10.1007/s00423-020-01953-5

Anton F. Engelsman

antonengelsman@me.com

1 Department of Surgery, Academic Medical Center, University of Amsterdam, PO Box 22660, 1100 AZ Amsterdam, The Netherlands

2 Department of Surgery, Groningen University Medical Center, University of Groningen, Groningen, Netherlands

3 Department of Surgery, Erasmus Medical Center, University Rotterdam, Rotterdam, Netherlands

4 Department of Nephrology, Leiden University Medical Center, University of Leiden, Leiden, Netherlands
Department of Surgery, Leiden University Medical Center, University of Leiden, Leiden, Netherlands

6 Department of Nephrology, Groningen University Medical Center, University of Groningen, Groningen, Netherlands

7 Department of Nephrology, Erasmus Medical Center, Erasmus University Rotterdam, Rotterdam, Netherlands

8 Department of Nephrology, Academic Medical Center, University of Amsterdam, Amsterdam, Netherlands 